\title{
ESCOLAS CRIATIVAS E INCLUSÃO
}

\author{
Adalberto Duarte Pereira Filho \\ Maria Dolores Fortes Alves
}

\section{Resumo}

Incomodou-nos a relação da escola em que frequentavam os sujeitos da ONG que acolhia crianças e adolescentes abandonados, na qual fazíamos atendimento psicológico. A escola como um lugar onde somente as dimensões cognitivas e comportamentais eram valorizadas. Questionamos: como práticas pedagógicas criativas podem contribuir para a inclusão escolar dos sujeitos em suas múltiplas dimensões? Buscamos compreender a relação entre a criatividade e a construção de escolas inclusivas. Em um estudo de caso de natureza quanti-qualitativa ofertamos para 18 professores da escola que atendia os sujeitos da ONG, um curso realizado em 3 (três) encontros presenciais, intitulado Educação em Direitos Humanos, Valores Transdisciplinares e Formação de Professoras/es. Para coleta dos dados aplicamos em 16 cursistas, o Instrumento para Valorar o Desenvolvimento de Instituições Educativas - VADECRIE (TORRE, 2012). Na análise, utilizamos a estatística descritiva. A partir dessa experiência compreendemos que a criatividade pode contribuir para a promoção de espaços inclusivos. Verificamos que, uma escola criativa é um lugar em constante movimento Torre (2013). É um lugar que nos faz transcender, onde a relação empática nutre as relações humanas. Essa escola legitima o melhor de seus professores e alunos. A escola criativa rasga o véu do tradicional e convoca à inovação e, igualmente, à inclusão, pois convoca-nos a construir um espaço de pertencimento de todos.

Palavras-chave: inclusão; escolas criativas; complexidade; transdisciplinaridade.

\section{CREATIVE SCHOOLS AND INCLUSION}

\begin{abstract}
We were bothered by the relationship between the school where the subjects of the NGO that attended abandoned children and adolescents attended, in which we did psychological care. The school as a place where only the cognitive and behavioral dimensions were valued. We ask: how can creative pedagogical practices contribute to the school inclusion of subjects in its multiple dimensions? We seek to understand the relationship between creativity and the construction of inclusive schools. In a case study of a quantitative and qualitative nature. We offered to 18 teachers from the school that attended the subjects of the NGO, a course held in 3 (three) face-to-face meetings, entitled Education in Human Rights, Transdisciplinary Values and Teacher Training. To collect the data, we applied the Instrument for Valuing the Development of Educational Institutions - VADECRIE, in TORRE (2012) in 16 course participants (TORRE, 2012). In the analysis, we used descriptive statistics. From this experience we understand that creativity can contribute to the promotion of inclusive spaces. We found that, a creative school is a place in constant movement, Torre (2013). It is a place that makes us transcend, where the empathic relationship nourishes human relationships. This school legitimizes the best of its teachers and students. The creative school tears the veil of the traditional and calls for innovation and, equally, inclusion, because it calls on us to build a space for everyone to belong.
\end{abstract}

Keywords: inclusion; creative schools; complexity; transdisciplinarity. 


\section{ESCUELAS CREATIVAS E INCLUSIÓN}

Resumen

Nos inquietó la relación de la escuela a la que asistían los sujetos de la ONG que acogía a los niños y adolescentes abandonados, en la que ofrecíamos atención psicológica. La escuela como un lugar donde sólo se valoraban las dimensiones cognitivas y de comportamiento. Nos preguntamos: ¿cómo pueden las prácticas pedagógicas creativas contribuir a la inclusión escolar de los temas en sus múltiples dimensiones? Buscamos comprender la relación entre la creatividad y la construcción de escuelas inclusivas. En un caso de estudio cuantitativo-cualitativo, ofrecimos a 18 profesores de la escuela que asistían a las asignaturas de la ONG un curso celebrado en 3 (tres) encuentros presenciales, titulado Educación en Derechos Humanos, Valores Transdisciplinarios y Formación de Profesores. Para la recolección de datos, se aplicó el Instrumento de Valoración del Desarrollo de las Instituciones Educativas - VADECRIE (TORRE, 2012) a 16 profesores. En el análisis utilizamos estadística descriptiva. A partir de esta experiencia entendemos que la creatividad puede contribuir a la promoción de espacios inclusivos. Comprobamos que una escuela creativa es un lugar en constante movimiento (TORRE, 2013). Es un lugar que nos hace trascender, donde la relación empática nutre las relaciones humanas. Esta escuela legitima lo mejor de sus profesores y estudiantes. La escuela creativa rasga el velo de lo tradicional y pide innovación e, igualmente, inclusión, porque nos llama a construir un espacio de pertenencia de todos.

Palabras clave: inclusión; escuelas creativas; complejidad; transdisciplinariedad.

\section{INTRODUÇÃO}

O interesse em desbravar essa temática insurge a partir de nossa experiência empírica e de atuação psicológica na educação em uma ONG que acolhia crianças e adolescentes abandonados. A equipe interdisciplinar composta por psicólogo, por assistente social e por pedagoga se tornava o grupo responsável pelo acompanhamento do desenvolvimento desses sujeitos, inclusive por seus desempenhos escolares. Em situação inusitada essa equipe da qual fazíamos parte enquanto psicólogo foi requisitada sucessivas vezes para comparecer à escola pública onde cerca de $50 \%$ das crianças acolhidas estudavam. No entanto, à exceção do primeiro convite, todos os demais chamados tiveram como mote nos advertir acerca do comportamento transgressor de uma criança de 10 anos de idade.

$\mathrm{Na}$ primeira das reuniões foi passada a informação de que a escola estava implantando a proposta de tempo integral e nesse sentido, exigia colaboração dos pais ou responsáveis na manutenção da disciplina (ONG, 2017). A escola mais uma vez esperava que as crianças, diferentes em seus percursos de vida tivessem, todas, o mesmo comportamento dócil e passivo. Imperava a necessidade de que as crianças se comportassem obedecendo a um padrão único por meio do qual os gestores pudessem prever e controlar as posições e as velocidades desses sujeitos e assim determinar os rumos desse movimento. A equipe interdisciplinar da ONG foi chamada outras seis vezes por essa escola para comunicar a conduta transgressora dessa criança de 10 anos. Ao longo dessas reuniões, a diretora desta escola pressionava para que atestássemos algum transtorno mental que justificasse o comportamento transgressor daquela criança. Esse fenômeno foi identificado na literatura como patologização da vida, que pode ser entendido como ato de transformar características afetivas e comportamentais em doença e ou desordem (CANGUILHEM, 2009). A exemplo do que a diretora estava chamando de comportamento transgressor é possível destacar, o episódio "da quebra da lâmpada fluorescente" (ONG, 2017, p. 38). O fato ocorrido aconteceu no horário do intervalo quando, essa criança, foco das reuniões, brincava com um peão e "[...] este objeto dançante aos olhos do pequeno infante foi impulsionado pela força e euforia da brincadeira 
e certeiramente destruiu uma das lâmpadas da escola" (ONG, 2017, p. 39). Diferente das reuniões anteriores, a sexta e última reunião contou com a presença do Conselho Tutelar, do departamento jurídico e da coordenação de educação especial da Secretaria Municipal de Educação de Maceió (SEMED), a assistente social, dois representantes do segmento de pais do Conselho Escolar e a professora da sala de recursos da escola.

Contrariando o parecer da equipe interdisciplinar da $\mathrm{ONG}$, que atestava que aquela criança não sofria de nenhuma psicopatologia, a diretora da escola conduziu a reunião solicitando a todos os segmentos presentes que dessem nome ao transtorno que a criança em tela possuía e informasse a terapêutica medicamentosa que deveria ser aplicada. Desta maneira a direção da escola transformara problemas de ordem psicossocial em demanda médica. Em discordância a tal postura, foram então apresentados aos presentes os resultados das sucessivas avaliações psicológica e psiquiátrica as quais a criança havia sido submetida e que atestavam total ausência de psicopatologia. A equipe interdisciplinar da ONG informou no relatório que "[...] a escola entendia dessa forma por só conseguir enxergá-lo através das lentes do preconceito que marca a trajetória de crianças negras, pobres e que por terem sido abandonados/as por suas famílias conheceram a dura realidade das ruas" (ONG, 2017, p. 40). Verifica-se, assim que, de forma consciente ou não, "[...] sempre estamos ensinando a favor de alguma situação ou de alguém, contra alguma situação ou alguém” (ALVES, 2013, p. 175).

A reflexão sobre esse caso reacendeu o incômodo epistemológico (FREIRE, 2018) em compreender os mecanismos que faziam com que as escolas insistissem em negar os sujeitos em seus múltiplos aspectos: "[...] razão, a emoção, a pulsão; incluindo o lúdico, o irracional e a poesia, enquanto expressões das emoções, sentimentos e intuições humanas" (ALVES, VIDINHA, 2016, p. 2). Esse incômodo nos mobilizava a buscar entender por que esses sujeitos, já tão excluídos, eram vistos pela escola, que deveria ser um lugar de inclusão, sob uma ótica normalizadora perpassada por formas adoecidas descontextualizadas de suas histórias de vida (CANGUILHEM, 2009).

Contrariando esse cenário, existia uma escola que contrastava com as demais. Nessa escola estava matriculado um dos adolescentes abrigados na ONG. Esse adolescente de fato sofria de uma patologia neurológica, uma deficiência intelectual. No entanto, tal diagnóstico não o impediu de ser visto nesta escola para além de sua patologia. Percebíamos que nesta escola esse adolescente conseguia avançar tanto do ponto de vista cognitivo, quanto em suas múltiplas dimensões enquanto sujeito. Esta escola sabia das condições desse adolescente e mesmo assim conseguia desenvolver práticas pedagógicas que contribuam efetivamente para que aquele fosse um ambiente no qual esse sujeito se sentia incluído. Ele não era visto como um aluno com deficiência e sim tratado como um adolescente em meio a tantos outros, com limitações e potencialidades. Em face do paradoxo que se apresentava entre uma escola que queria atestar a psicopatologia de uma criança que não a possuía e outra escola que tinha encontrado meios criativos para que um adolescente com deficiência intelectual fosse visto para além de suas limitações, me senti impelido a buscar dispositivos teóricos que me ajudassem a compreender o que diferenciava essas escolas. Diante dessa contradição, surgiu o problema dessa investigação: como práticas pedagógicas criativas podem contribuir para a inclusão escolar dos sujeitos compreendidos em suas múltiplas dimensões?

Para responder a essa questão buscou-se compreender a relação entre a criatividade e a construção de escolas inclusivas. Com os objetivos de evidenciar os movimentos criativos da escola para a construção de um ambiente inclusivo. E de modo específico, compreender as contribuições da complexidade, da transdisciplinaridade para a construção de escolas criativas; identificar as múltiplas dimensões da escola em que a criatividade precisa ser mobilizada no sentido de construir 
um ambiente escolar inclusivo; analisar o quanto essas múltiplas dimensões, por meio das quais a criatividade se manifesta, contribuem para a construção de um ambiente inclusivo.

O conceito de criatividade na contemporaneidade tem sido veículo para o enfrentamento de problemas nos âmbitos pessoais e das organizações, através de estratégias de reformulação para o combate de paradigmas e resistências. A criatividade assim é uma possibilidade ampla na resolução de problemas atuais a exemplo do que trazemos aqui: as demandas da educação. Para Milian e Wechsler (2018) a combinação afinada dessas variáveis é capaz de conceber a realização pessoal e institucional ainda que transcendentais ao humano. Atuar criativamente implica superar a visão reducionista do conceito. É implicar-se no processo de explorar, especular ou contribuir com ideias originais.

No ambiente educacional, a criatividade é um termo comum, "[...] é o ingrediente necessário para realizar a transformação que sonhamos" (TORRE, PUJOL, 2007, p. 25). Problemas educacionais tais como a evasão, a distorção idade-série, a exclusão, as atitudes antissociais, as drogas lícitas e ilícitas na escola, a gravidez na adolescência, o consumismo, o bullying, a patologização da vida, demandam criatividade para a invenção de novas alternativas. Outros fatores comportamentais também surgem no cenário como a ausência de limites para nortear de forma ética e afetiva as relações, ausência de diálogo, do estabelecimento e a internalização de regras civilizatórias de convivência, a fluidez nas relações que são cada vez mais virtuais ou autobiográficas.

Os sujeitos que se fecham em si mesmos e/ou vivem interações humanas mediadas exclusivamente pela internet, estabelecendo relações de solidão interativa, a onda do consumo mobilizada pela mídia, a alta produção de lixo e seus impactos na natureza, a fome, a desigualdade, a ausência de empatia que produz a exclusão das diferenças são uma pequena amostra dos problemas que compõem a realidade fracassada da educação atualmente, são inquietudes que passam pelos efeitos das mudanças sociais, econômicas e políticas.

Frente a essas questões uma nova perspectiva pedagógica inclusiva precisa ser pensada. Alternativas como a transdisciplinaridade e a ecoformação são formas de pensar o humano e as questões da humanidade de forma ampla, complexa, que busquem ressignificar e imprimir valores humanos, atitudes humanas e responsabilidades com os humanos, com a natureza e com o cosmos. A criatividade enquanto expressão humana do humano faz um corte civilizatório que nos situa diferentes dos demais seres vivos, nos faz reinventar.

A maior tragédia de nossos tempos é a manutenção da escola tradicional. Este modelo permanece vivo graças à respiração assistida que recebe diariamente do sistema político que o mantém. Apesar das constantes críticas que convocam à mudança desse modelo escolar vigente por educadores contemporâneos (ALVES, 2016; MORAES, 2004; TORRE, 2012; SUANNO, 2013; FREIRE, 2018; MORÁN, 2014), o modelo tradicional persiste. Esse tipo de modelo educacional, também conhecido como clássico, ou paradigma newtoniano, consiste em um paradigma conservador, a experiência do aluno não conta e dificilmente são proporcionadas atividades que envolvam a criação. A prática pedagógica tradicional leva o aluno a caracterizar-se como um ser subserviente, obediente e destituído de qualquer forma de expressão. O aluno é reduzido ao espaço de sua carteira, silenciando sua fala, impedido de expressar suas ideias. A ação docente concentra-se em criar mecanismos que levem a reproduzir o conhecimento historicamente acumulado e repassado como verdade absoluta (BEHRENS, 2007, p. 53).

Esse paradigma propõe a primazia da razão sobre a emoção, está calcado na racionalidade técnica, sustenta-se no modelo curricular dominante fundamentado em disciplinas desarticuladas entre em si que privilegiam a transmissão de informações. As escolas tradicionais não acompanham 
as mudanças da sociedade, esse modelo de escola é uno, o processo de ensino e avaliação é igual para todos e exige resultados previsíveis.

Precisamos suplantar o modelo clássico em detrimento de um modelo criativo e inovador que ensina o aluno a conhecer, a construir seus projetos de vida e a conviver com os demais. Dentro de uma perspectiva criativa, se ensina a aprender e que o erro é parte do processo, que o conhecimento acontece numa relação simbiótica, ou seja, da junção indissociável entre errar e acertar, ambas são parte indispensável do processo de aprender (ALVES, PEREIRA FILHO, 2017).

O modelo criativo é disruptivo, é complexo, redesenha a prática pedagógica. A proposta é flexível, os espaços físicos são múltiplos, a sala de aula pode ser o jardim, a horta e nesse ambiente se aprende a calcular a área, a verificar a posição do vento, polinização, mas também a como fazer um chá, a não usar agrotóxico, a partilhar, a conviver e etc. O estudante aprende no seu próprio ritmo, necessidade, em grupos, com supervisão de professores orientadores. A escola criativa contribui para mobilizar as competências desejadas, intelectuais, emocionais, pessoais e comunicacionais; os sujeitos aprendem a avaliar situações, a expressar seus pontos de vista, a escutar o antagônico, exercitam a tolerância, estão implicados nas escolhas, assumem os riscos, aprender pela descoberta, caminham do simples para o complexo.

A partir da Tabela 1 podemos visualizar um comparativo entre o modelo tradicional e a proposta das escolas criativas.

Tabela 1: Comparativo do modelo tradicional e a proposta da escola criativa

\begin{tabular}{|c|c|}
\hline Modelo educacional clássico & Modelo educacional criativo \\
\hline $\begin{array}{l}\text { O conteúdo e as habilidades se fundamentam na } \\
\text { aprendizagem. Centram-se nas disciplinas, como } \\
\text { ciências, línguas e história. Desvaloriza as } \\
\text { habilidades para a vida. }\end{array}$ & $\begin{array}{l}\text { Envolve os alunos em atividades de aprendizagem } \\
\text { que os prepararão melhor para a vida. }\end{array}$ \\
\hline $\begin{array}{l}\text { A mensuração de resultados ocorre por meio de } \\
\text { notas e testes. O conhecimento é mensurável e } \\
\text { pode ser comparado com outros grupos, o que } \\
\text { prevalece é o número. }\end{array}$ & $\begin{array}{l}\text { Investem para que os alunos se destaquem nas áreas } \\
\text { em que têm interesse, incentiva a desenvolver } \\
\text { competências e qualidades que farão do mundo um } \\
\text { lugar melhor. Prima por valores de convivência } \\
\text { como tolerância, e por desenvolver um olhar mais } \\
\text { humano. }\end{array}$ \\
\hline $\begin{array}{l}\text { Currículo rigoroso e uniforme comum para todos } \\
\text { os alunos. Objetiva aumentar o nível para atender } \\
\text { exigências acadêmicas. As atividades são únicas } \\
\text { para todos, desconsiderando o potencial } \\
\text { individual e o ritmo de aprendizagem. }\end{array}$ & $\begin{array}{l}\text { Auxilia os alunos a se tornarem o que efetivamente } \\
\text { são, elevando suas consciências para se posicionarem } \\
\text { na vida consigo mesmos, com os outros. Visa valores } \\
\text { transpessoais. }\end{array}$ \\
\hline $\begin{array}{l}\text { Os resultados são comparativos entre estudantes, } \\
\text { instituições e estados, países. A evolução do } \\
\text { aprendente em relação a ele mesmo não é } \\
\text { considerada. Homogeneização da subjetividade. }\end{array}$ & $\begin{array}{l}\text { Dá aos professores e alunos mais controle sobre seu } \\
\text { ambiente de aprendizagem. Prima pela autonomia do } \\
\text { professor na hora do planejamento e criações } \\
\text { favoráveis. Cultiva a autonomia, a responsabilidade e } \\
\text { a independência. }\end{array}$ \\
\hline $\begin{array}{l}\text { As alegações que classificam os sujeitos são } \\
\text { discutidas por dados de pesquisa científica, que } \\
\text { atestam o resultado bom e o ruim, a partir do } \\
\text { global. Abortando que cada sujeito é um universo } \\
\text { possível de aprender. }\end{array}$ & $\begin{array}{l}\text { A abordagem volta-se ao desenvolvimento humano, } \\
\text { para o aumento da motivação e o entusiasmo. }\end{array}$ \\
\hline
\end{tabular}


DOI: $10.12957 /$ teias.2021.59025

\begin{tabular}{|c|c|}
\hline $\begin{array}{l}\text { Parâmetros traçados politicamente para } \\
\text { apresentar estatísticas que atestem a eficácia do } \\
\text { programa de ensino. }\end{array}$ & $\begin{array}{l}\text { Os atores interagem e decidem em gestão } \\
\text { democrática e participativa. }\end{array}$ \\
\hline
\end{tabular}

Fonte: Elaborado pelo autor - Adaptado de Torre e Pujol (2007).

Parece-nos que cada escola tende a priorizar um conceito diferente de criatividade e, em decorrência disso, dinamizam processos pedagógicos distintos da gramática criativa que circunscrevemos. Geralmente nos defrontamos com práticas centradas em competição, exclusão e fragmentação, estimulando uma criatividade limitada ao desenvolvimento de estratégias didáticas vinculadas à reprodução linear de conhecimentos historicamente acumulados (SUANNO, 2009). O sentido que tomamos para abordar a criatividade é sustentado pelo paradigma ecossistêmico, que, segundo Moraes (2004, p. 42), é "[...] construído a partir de intercâmbios nutridores entre o sujeito e o objeto, mediante diálogos, interações, transformações e enriquecimentos mútuos". O lastro teórico ecossistêmico prioriza a solidariedade, a inclusão e um ensino contextualizado para aplicabilidade na vida dos sujeitos. Uma escola criativa é um lugar em constante movimento. Como nos diz Torre (2012), é um lugar que nos faz transcender, onde a relação empática nutre as relações humanas, é um lugar em que a realidade é recriada, que legitima o melhor de seus professores e alunos e é capaz de transbordar afetivamente.

O processo de aprendizagem está vinculado às demandas da atualidade de forma amplificada, já que consideramos as incertezas no futuro, as potencialidades humanas, no intuito de educar cidadãos planetários, sujeitos interessados pelas questões humanas e cósmicas.

A perspectiva planetária, está ligada aos valores humanos, à paz, ao meio ambiente, tem por finalidade favorecer nas pessoas a compreensão das múltiplas dimensões do mundo atual e do futuro e a participação eficaz nos desafios inerentes ao universalismo, a diversidade, adotando um enfoque sistêmico das realidades complexas (BOAVENTURA, 2001). A educação planetária desenvolve nos sujeitos convicções e crenças fiéis a valores humanos reconhecidos em civilizações como: confiança, responsabilidade, justiça, reputação, amizade, solidariedade, igualdade e equidade. É educar para a compreensão de que os povos estão interligados e que as ações humanas são recursivas e afetam aos outros em algum grau, ou seja, somos todos interligados ecossistematicamente. Para Moraes (2004) o paradigma ecossistêmico é o ponto de separação entre a educação do futuro e a educação tradicional. Para Torre (2007) podemos reconhecer que há uma diversidade de nomenclaturas utilizadas pelos pesquisadores para indicar os dois paradigmas. Assim, Moraes (2004) o situa como paradigma positivista e paradigma ecossistêmico ou emergente.

Afirmamos, a partir de Torre (2007), que a escola criativa é alicerçada na transdiciplinaridade e na complexidade. As escolas criativas avançam na perspectiva de "[...] superar a cegueira do conhecimento" (MORIN, 2011, p. 26) e por isso se vinculam ao pensamento complexo (MORIN, 2015), quando "[...] não há separatividade, inércia ou passividade entre os conhecimentos, tudo está relacionado, conectado e em renovação contínua" (MORAES, 2004, p. 61). A transdisciplinaridade surge como solução à ideia da desconexão entre os saberes. Por consequência dessa divisão dos saberes, os humanos passaram a não atribuir sentido às ciências e às dimensões vastas intrínsecas a vida. Deste modo, a transdisciplinaridade seria uma maneira de religar/reconectar os saberes às dimensões da vida, dada a complexidade inerente à realidade humana. Em seu arcabouço, não existe verdade absoluta. As verdades podem coexistir em um mesmo espaço e realidade, numa relação dialógica e dialética. Há uma tentativa de relacionar os saberes científicos seculares a outros saberes humanos e sobre eles colocar sempre a dúvida e a relativização, proporcionando terreno para que professores e alunos possam encontrar suas 
DOI: $10.12957 /$ teias.2021.59025

próprias verdades, de modo criativo e responsável enquanto ser planetário homo complexus sapiens demens.

A transdisciplinaridade busca atentar para os problemas reais da sociedade e preparar os sujeitos para a vida e para a realidade moderna que é complexa e impossível de ser explicada em termos simplistas e exatos. Para tanto seria necessário trabalhar a partilha e o trabalho coletivo. A complexidade humana não deve ser reduzida a paradigmas prontos e postos como explicação para uma regência determinista da humanidade. Entende-se a necessidade de se compreender que o mundo é uma constante construção, operada por todos, e somos muitos, e somos múltiplos.

O conhecimento é o caminho que leva o sujeito a autonomia. A transformação só é possível diante de ações pensadas em coletivo, ouvindo a todos, e permitindo sua igual participação, pois nisto deve consistir a cidadania; a pessoa com deficiência deve ter o direito de autonomia e independência igual aos demais, a partir do olhar para suas capacidades acima de suas limitações. O processo de conhecimento é direito de todos e ocorre por meio do ensino e aprendizagem, que devem ser articulados de maneira que alcance de forma efetiva a cada sujeito dentro das especificidades que carregam em seu corpo e sua história; entendendo que cada ser está em constante e permanente desenvolvimento. O aluno é também agente ativo de seu próprio processo de aprendizagem, assim é importante que tudo que o constitui seja devidamente considerado, seus aspectos cognitivos, sociais e emocionais.

Para Torre (2007, p. 401), as escolas criativas se caracterizam por possuir:

[...] um referencial de ensino e aprendizagem baseado em autonomia, transformação, colaboração e busca do desenvolvimento integral; que partem dos interesses dos estudantes e de sua realidade, transcendendo o conhecimento científico, por meio do desenvolvimento de atitudes colaborativas, solidárias e conectadas com a vida; estimulam uma prática educativa flexível e aberta às emergências que precedem sua aplicação e às que surgem durante seu desenvolvimento; fomentam a resiliência dos estudantes e dos próprios docentes, que ressignificam seu pensamento enquanto ajudam a ressignificar o entorno.

A criatividade enquanto conceito surge para apontar caminhos possíveis de transformação na forma de funcionar das instituições educativas. Enquanto bússola da prática educativa, a criatividade visa à transformação institucional, já que a educação é a peça-chave no caminho para uma sociedade mais justa, tolerante e solidária. Com o objetivo de construir organizações mais abertas, compreensivas e transformadoras, o conceito de criatividade, a partir do paradigma ecossistêmico, convoca as instituições que reconhecem a necessidade de rever seus fundamentos, a produzirem conhecimentos e a trocá-los, reconhecer seus limites, e propor mudanças às suas inquietações.

Para Torre (2012, p. 19) “[...] a criatividade é um fenômeno que se move entre os atributos pessoais e as exigências sociais, porque em último caso, é a sociedade que promove e sanciona o valor ou a relevância das atividades criativas". A partir disso podemos situar que não estamos falando aqui de um modismo, ou num termo que pretenda qualificar um slogan publicitário. Há uma complexidade imensurável nessa categoria. Podemos pensar a partir da afirmativa acima que há um atravessamento social do conceito articulado com a educação, que resulta na possibilidade de pensar novas formas de fazer e compreender a prática pedagógica.

A criatividade está imbricada a elementos sociais e psicológicos do sujeito como a identificação e as predileções, que negociam com a realidade social e recriam possibilidades. É a forma de conduzir conjuntamente o processo de mudança, é agir, é um ato de criação. O termo 
criatividade tem figurado nos discursos dos membros da comunidade escolar na atualidade. Isso sinaliza para o intuito desses sujeitos de percorrerem o caminho na contramão de instituições que seguem um modelo cartesiano. No entanto, tais esforços ainda não são suficientes para uma genuína superação da lógica da educação tradicional. Para isso, é fundamental que tais discursos se apoiem no pensamento complexo e se materializem em propostas pedagógicas, práticas de ensino e formas de acompanhamento e avaliação ecossistêmicas e transdisciplinares. Esse movimento implica que nos cursos de formação de professores, a produtividade acadêmica dê lugar a uma concepção de formação integral dos sujeitos. Isso porque "[...] há uma responsabilidade social na criatividade" (SUANNO, 2013, p. 122) e para que essa criatividade se manifeste em suas máximas formas de expressão é fundamental que o espírito humano esteja livre de toda e qualquer amarra política, social, cultural ou econômica.

A partir dessas características fundamentadoras e conceituais, a proposta das escolas criativas sustenta sua prática a partir de pensamentos que mobilizam professores e alunos a transitarem nos conteúdos curriculares, de forma a vinculá-los a aplicabilidade prática, possibilitando a transformação da realidade. Pela via da criatividade é possível emergir uma nova escola que transcende, recria, transforma, incorpora a realidade. As instituições criativas vão mais adiante do lugar que partem, dão mais do que tem, ultrapassam o que delas é esperado, são escolas que reconhecem o lugar de cada um, que crescem por dentro e por fora, buscam o bem-estar individual, social e planetário. Para Torre (2007) a escola criativa não exige que uma nova escola se construa, mas que um novo modelo seja criado, e o que existe nela de inovador seja potencializado. Caminhamos contra o objetivo inicial da escola que sempre foi o de atender uma fatia muito específica da população, essa é a classe dominante, e de algum modo vem preparando a nova geração para assegurar que seu intento se perpetue. Para Suanno (2013) se trata de inserir novos e crus conceitos à escola, mas de, a partir deles, produzir sujeitos transformadores, inovadores, criativos e atuantes planetariamente. Conceitos teóricos como a inovação, a criatividade e a transdisciplinaridade são instrumentais pensantes para mudar a realidade educativa, sair do tradicional. Impomo-nos ao modelo, fundamentado na ordem clássica transmissora de conteúdo, reprodutora do conhecimento, orientada para o consumo, distante da realidade, que avalia o desempenho a partir da atribuição de nota, centrada em currículos desatualizados. Romper com esse padrão historicamente construído exige um enfrentamento à ordem política da elite que está unida para sustentar um sistema de dominação, privilégios e controle que os favorece e, também, ao anacronismo e inadequações diante dos tempos atuais (SUANNO, 2013).

A crítica à escola é um ato criativo, se considerarmos que a dialogicidade da análise faz repensar os desafios, os limites, os objetivos da escola, a filosofia, a prática de ensino, os modos de avaliação e de convivência, se possibilitar o emergir de um novo fazer. Uma escola criativa é aquela que reconhece o desejo de sê-la; e que provoca constantes mudanças no percurso do amadurecimento institucional, que implica assumir um lugar de não saber, ou seja, um lugar em que a busca pelo conhecimento é constante; é aquela que está aberta a discutir seus receios, seus intentos, compartilhar as aprendizagens com as pessoas, difundir as experiências de sucesso e socializar os erros, decidir democraticamente e registrar as reflexões (SUANNO, 2013). As escolas criativas se fundamentam nas incertezas, já que consideramos as verdades mutáveis, voláteis, esse modelo pode ser construído, desconstruído e reconstruído ao longo da história. É uma forma que convida a romper a obssessividade institucional, ou seja, a esse circuito repetitivo que impede outras construções. A educação criativa rasga o véu do tradicional e convoca à inovação. Escolas criativas são instituições educativas que desenvolvem as potencialidades institucionais, humanas, sociais e ambientais em uma perspectiva complexa, transdisciplinar (SUANNO et al., 2014). 
Não existe um modelo único de escola criativa, não há um molde que determine de forma engessada como devem ser. Mas podemos dizer que "[...] há indicativos de como identificar uma escola que tenha características de dialogar com o mundo e a atualidade. São escolas que criam, produzem e que se reinventam" como afirma Suanno (2014, p. 5).

As escolas têm seguido por caminhos distintos para entender que o ser humano precisa ser educado para além da cognição. Pensar na formação do ser humano é pensar a partir de uma razão sensível; significa educar para a formação de conceitos, para a capacidade de leitura crítica da realidade e para ser capaz de construir uma reflexão transformadora propositiva, mas conduzindo o sujeito a pensar em seus valores e sua postura em relação ao mundo. $\mathrm{Na}$ escola criativa, os indivíduos se transformam, porque começam a se preocupar com a coerência da sua relação com o meio ambiente. Preocupam-se com a alimentação, o modo de ser, as próprias prioridades nesse mundo que nos atropela com tanto trabalho, correria, atividades e, também, com o tempo necessário para estar em contato com a natureza. Essas escolas estão formando sujeitos capacitados a rever valores, princípios e opções.

A escola criativa objetiva um movimento de reencantar o ensino e, por consequência, a aprendizagem. Essa cadência no campo da educação está para além do conhecimento disciplinar, a aprendizagem criativa, implica conhecimento sobre e para a vida e engloba aspectos complexos da sociedade como as questões relacionais, ecológicas e planetárias do sujeito. Assim, a escola criativa escapa da linearidade do conhecimento, privilegia a condição unívoca do humano, que é ser dotado de consciência produtora de sentido e, também, o conhecimento complexo, transdisciplinar e multidimensional. É uma possibilidade exitosa para produção de uma escola inclusiva. Nesta perspectiva de uma escola para todos, a escola criativa considera as individualidades de cada aluno no seu processo de construção do conhecimento, quando a única semelhança entre os sujeitos é a diferença.

A escola criativa está atenta para uma esperança na educação inclusiva. Ela é produtora de ações pedagógicas que constroem novas formas de ensinar e de aprender. Assim caminha para a promoção da redução das desigualdades sociais e escolares, o que produz um movimento a favor da inclusão na contramão do que historicamente foi reclamado. Essas reivindicações buscaram a garantia de um lugar objetivo e subjetivo no espaço escolar, um ambiente capaz de acolher a diversidade. O que nos faz refletir que o cenário inclusivo no Brasil ainda está em construção, e demanda uma posição política para a edificação de um espaço para todos.

\section{METODOLOGIA}

Trata-se de um estudo de natureza quanti-qualitativa (SAMPIERI, COLLADO, LÚCCIO, 2013). Assim, elegemos como sujeitos da pesquisa as/os próprias/os professoras/es da escola em que o adolescente abrigado na ONG, com deficiência intelectual estudava. Assim das/os 19 professoras/es que compõem o quadro de recursos humanos desta escola, 18 compareceram à formação e 15 concordaram em participar desta pesquisa. A escolha desta escola como lócus de pesquisa se justifica pelo fato de que ela nos chamou atenção pelas práticas criativas que eram desenvolvidas no sentido de construir uma escola inclusiva. Com relação ao tipo de pesquisa, essa se caracteriza como um estudo de caso, uma investigação empírica de um fenômeno contemporâneo (YIN, 2005). Para a coleta dos dados, utilizamos o Instrumento para Valorar o Desenvolvimento de Instituições Educativas (VADECRIE). Esse instrumento caracteriza-se como artifício identificador de escolas criativas (TORRE, 2012). Apresenta dez categorias de investigação. São elas: (1) Liderança estimuladora e criativa; (2) Professorado criativo; (3) Cultura 
inovadora; (4) Criatividade como valor; (5) Espírito empreendedor; (6) Visão transdisciplinar e transformadora; (7) Currículo polivalente; (8) Metodologias e estratégias criativas; (9) Avaliação formadora e transformadora; (10) Valores humanos. Cada categoria agrupa 10 perguntas que indagam acerca de indicadores de criatividade. Tais perguntas são referidas por Suanno (2013) como indicadores que descrevem as categorias que os caracterizam respectivamente. Trata-se de questões fechadas que podem ser respondidas numa escala de 1 (um) a 10 (dez). Quanto maior for o valor dado como resposta a cada pergunta, maiores serão as evidências da presença desse indicador de criatividade. Nesse sentido o 1 (um) representaria o nível mais baixo da presença desse indicador de criatividade, e o 10 (dez) seu nível máximo (TORRE, 2012; SUANNO, 2013).

Tendo em vista a necessidade de identificar escolas criativas, Suanno (2013) reformulou a clássica escala de 1 (um) a 10 (dez) do instrumento VADECRIE. Segundo Pereira (2004, p. 65) uma escala de dez pontos (de 1 a 10) "[...] aportaria um refinamento de precisão à medida, mas, em contrapartida, implicaria a perda de acurácia, já que dificilmente o pesquisador disporia de dez categorias distintas para classificação qualitativa do fenômeno estudado". Nesse sentido, Suanno (2013) propôs uma correspondência entre intervalos na escala numérica, conceitos qualitativos e seus significados. Essa correspondência pode ser verificada a partir da Tabela 2.

Tabela 2: Relação entre a escala numérica, os conceitos qualitativos e seus significados

\begin{tabular}{|l|c|c|}
\hline \multicolumn{1}{|c|}{ Presença da característica ou indicador } & $\begin{array}{c}\text { Valorização } \\
\text { qualitativa }\end{array}$ & $\begin{array}{c}\text { Valorização } \\
\text { numérica }\end{array}$ \\
\hline Nunca ou quase nunca & $\mathrm{D}$ & $1-2$ \\
\hline Às vezes. Ocasionalmente & $\mathrm{C}$ & $3-4-5$ \\
\hline Muitas vezes ou ocasiões. Existem evidências do indicador & $\mathrm{B}$ & $6-7-8$ \\
\hline $\begin{array}{l}\text { De contínuo. Evidências claras de aparição do indicador ou } \\
\text { característica. }\end{array}$ & $\mathrm{A}$ & $9-10$ \\
\hline
\end{tabular}

Fonte: Suanno (2013, p. 82)

O cenário de coleta de dados se forjou após um curso de formação para o corpo docente intitulado Educaşão em Direitos Humanos, Valores Transdisciplinares e Formação de Professoras/es. Essa formação foi realizada na própria escola em três encontros presenciais, quando realizamos a coleta dos dados desta pesquisa, por meio da aplicação do instrumento VADECRIE. A aplicação desse instrumento aconteceu ao final do último encontro da formação. É importante salientar que todos os cuidados éticos foram tomados. As/os professoras/es presentes foram convidadas/os a participar da pesquisa. Para as análises desses dados, utilizamos a estatística descritiva, mais especificamente as análises das medidas de tendência central (SAMPIERI, COLLADO, LÚCCIO, 2013). As medidas de tendência central, segundo esses autores, "[...] são pontos em uma distribuição obtida, os valores médios e centrais destas que nos ajudam a posicioná-la dentro da escala de mensuração" (SAMPIERI, COLLADO, LÚCCIO, 2013, p. 307). Como o VADECRIE utiliza categorias nominais, Pereira (2004) afirma que a medida de tendência central pertinente para essa análise é a moda. Para Sampiere, Collado e Lúcio (2013, p. 307) “[...] a moda é a categoria ou pontuação que ocorre com maior frequência, ela é utilizada com qualquer nível de mensuração".

\section{ANÁLISE}

Uma escola criativa desponta através de projetos inovadores que intentam com afinco a integração do indivíduo, com a sociedade e a natureza. Esses fatores confluem num oceano de 
complexidades teóricas, objetivas e subjetivas. Essas águas compõem saberes nos quais o fundamento do pensar complexo propõe a unidade do conhecimento, que surge da forja dos conhecimentos fragmentados. Morin (2003) não nos propõe a busca pelo novo, mas o religar do velho, que está separado. O pensamento complexo trata de unir os conhecimentos das disciplinas, atenta-se para a incerteza, e é capaz de (re)unir como um elo as partes da corrente. Reconhece o singular, o individual e o concreto. Pensar complexamente é análogo a obra de um tecelão que produz sua obra fio a fio. Uma escola criativa pensa seus aprendentes de forma complexamente singular fio a fio, mas, como pertencentes ao todo. Sustenta suas práticas pedagógicas, com vistas à religação do humano ao cosmos. E compreende que sua prática se faz no coletivo, como um tecido, que é "tecido junto" (MORIN, 2005, p. 13).

A escola criativa destoa do modelo tradicional obscurecido, esta é inovadora, libertadora, curiosa, que busca a construção de cidadãos planetários capazes de enxergar, pensar e agir sobre os problemas ecossistêmicos, e em suas relações humanas. Sem a criatividade nesse processo a posição complexa do humano se perde em nome de uma lógica simplista. Precisamos convocar uma forma criadora que capte e religue a complexidade dos sujeitos aprendentes (MORAES, 2015). Nesse sentido, ao termos observado as respostas dos sujeitos dessa pesquisa em cada uma das categorias do VADECRIE, se faz necessário também ter uma visão panorâmica do todo. Assim, organizamos a distribuição de frequência dos conceitos atribuídos a partir das mensurações de cada uma das respostas dos sujeitos da pesquisa na Tabela 3 também importamos esses dados para a Figura 1 com o objetivo de visualizar os percentuais de cada um desses conceitos em relação ao todo.

Tabela 3: Síntese quantitativa dos conceitos nas categorias do VADECRIE

\begin{tabular}{|l|c|c|c|c|c|}
\hline Categorias do VADECRIE & A & B & C & D & Total \\
\hline Liderança criativa & 89 & 59 & 1 & 1 & 150 \\
\hline Professorado criativo & 85 & 65 & 0 & 0 & 150 \\
\hline Cultura inovadora & 88 & 61 & 1 & 0 & 150 \\
\hline Criatividade como valor & 96 & 54 & 0 & 0 & 150 \\
\hline Espírito empreendedor & 106 & 43 & 0 & 1 & 150 \\
\hline Visão transdisciplinar e transformadora & 96 & 54 & 0 & 0 & 150 \\
\hline Currículo polivalente & 103 & 47 & 0 & 0 & 150 \\
\hline Metodologia estratégica e didática & 89 & 57 & 4 & 0 & 150 \\
\hline Avaliação formadora e transformadora & 93 & 52 & 5 & 0 & 150 \\
\hline Valores humanos & 98 & 51 & 1 & 0 & 150 \\
\hline Total & $\mathbf{9 4 3}$ & $\mathbf{5 4 3}$ & $\mathbf{1 2}$ & $\mathbf{2}$ & $\mathbf{1 5 0 0}$ \\
\hline
\end{tabular}

Fonte: Os autores 
DOI: $10.12957 /$ teias.2021.59025

Figura 1: Síntese percentual dos conceitos nas categorias do VADECRIE

Fonte: Os autores

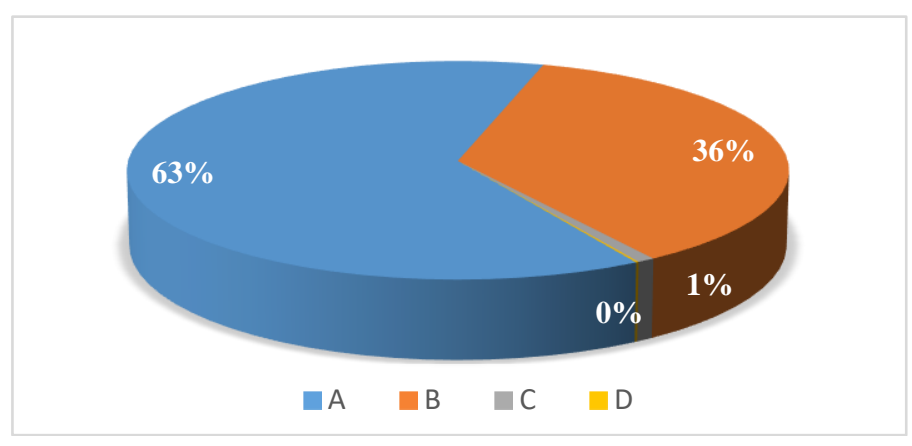

Segundo Suanno (2013, p. 254), para que a escola seja considerada como "[...] efetivamente criativa, $60 \%$ das respostas dos participantes devem estar nos conceitos $\mathrm{A}$ e $\mathrm{B}$, sendo que, no mínimo, 31\% das respostas devem estar no conceito A". A partir da Figura 1 podemos afirmar que o colégio analisado supera esse percentual. Assim, pudemos, com o instrumento VADECRIE, atestar que a instituição em pauta seria uma instituição criativa.

Apesar de constatarmos pelas lentes do VADECRIE e legitimar a escola investigada como criativa, é importante que não percamos de vista o olhar das partes que o compõem. Ao longo das análises de cada uma das categorias deste instrumento, percebemos que alguns sujeitos se destacaram por atribuírem valores bastante discrepantes das modas. Observamos também que, na maioria dos casos, os sujeitos que realizavam esses movimentos eram os mesmos. Esse sintoma, sendo recorrente ao longo de todo o instrumento, indica que essas partes não estão bem integradas ao todo da escola. Do mesmo modo, se o todo não se sensibilizar com o afastamento das partes, esse todo compromete sua visão criativa e inclusiva. O que se observa é que o olhar quantiqualitativo é imprescindível nesse tipo de pesquisa. Ao trabalhar com um grande volume de dados (1500 respostas), se ganha em precisão e ao refinar o olhar acerca de cada uma das respostas dos sujeitos se ganha em acurácia (PEREIRA, 2004). Assim, o fato de diagnosticarmos essa escola como instituição criativa, não a exime de cuidar para que seus indicadores não só se mantenham como melhorem ainda mais. Os desafios impostos pela realidade contemporânea e as contradições sociais que emergem pela dinâmica planetária exigem dos profissionais da educação que estejam em constante processo de formação, de diálogo, de escuta e de articulação com o sujeito, a sociedade e natureza. É inegável que essa escola demonstra movimentos criativos no sentido da construção de um ambiente inclusivo. Esse dado pode ser constatado a partir dos percentuais das respostas dos profissionais que estão na linha de frente do fazer pedagógico. Estatisticamente, os indicadores de criatividade desta escola indicam sua preocupação com a inclusão dos sujeitos. $\mathrm{O}$ olhar complexo e transdisciplinar presente nesta instituição, desde a proposta pedagógica até as práticas educativas, contribuiu sobremaneira para a manifestação desses resultados. No entanto, como se pode perceber, é imprescindível que as instituições que buscam pela via da criatividade a constituição de espaços inclusivos, jamais percam de vista a necessidade de valorizar individualmente das dimensões humanas do humano. 


\section{CONSIDERAÇÕES FINAIS}

A partir dessa experiência investigativa que envolveu estudos teórico-bibliográficos e a análise do caso do colégio da educação básica de Alagoas, fomos nos dando conta de como a criatividade pode contribuir para a promoção de espaços inclusivos. Verificamos que, a partir de práticas pedagógicas criativas é possível pensar uma escola que valoriza o aprendizado, a sensibilidade e o desenvolvimento afetivo-social; que pensa a inclusão no cotidiano e em todos os seus projetos. Isso possibilita amplificar a forma de ver o humano para além de suas impossibilidades, faz estabelecer uma relação de confiança a favor da superação das limitações objetivas e subjetivas.

Nesse contexto a criatividade faz repensar as formas de enxergar e produzir o humano, assim como nas formas de construir o conhecimento nesse espaço. Isso implica uma mudança atitudinal que só é possível por meio do rompimento com as formas tradicionais de ensinar. Além disso, implica também renunciar as antigas alianças com a exclusão. Ser escola criativa é possibilitar a compreensão dos sujeitos em suas múltiplas dimensões. Movimentar-se criativamente na direção da inclusão é pensar o humano como único. Assim as diferenças deixam de ser privilégios classificatórios para se inscrever como uma condição plural e unívoca. Esse movimento desencadeia um processo de posicionar-se criticamente sobre o fazer pedagógico.

Conduzidos pela bússola da complexidade, professores e alunos criativos passam a criar e integrar em seu cotidiano a unificação do pensamento. Produzindo contextualizações e problemas singulares e coletivos, simples e complexos para uma busca criativa por respostas inacabadas. Passam a tecer conjuntamente suas tapeçarias de conhecimento. Assim, podemos dizer que, certamente, o pensamento complexo é uma das formas mais coerentes para perceber e superar os desafios para a educação na atualidade, notadamente no que diz respeito às escolas e seus atores diários, já que superam o formato anterior cujo comportamento é compartimentado. A criatividade abre as portas das salas de aula e do conhecimento. A partir dos elementos teóricos da complexidade, da transdisciplinaridade e da ecoformação se faz possível pensar a escola criativamente. Por essa via, a utopia que habita o imaginário social sobre as escolas brasileiras tornase possível.

Intentamos buscar no colégio locus da pesquisa indícios de criatividade e por esse caminho verificar se esta era ou não criativa. Assim, constatamos que esta é uma escola criativa. Todavia o fato de diagnosticarmos essa escola como instituição criativa, não a exime de cuidar para que seus indicadores não só se mantenham como melhorem ainda mais. Os desafios impostos pela realidade contemporânea e as contradições sociais que emergem pela dinâmica planetária exigem dos profissionais da educação que estejam em constante processo de formação, de diálogo, de escuta e de articulação com o sujeito, a sociedade e natureza.

É inegável que essa escola demonstra movimentos criativos no sentido da construção de um ambiente inclusivo. Esse dado pode ser constatado a partir dos percentuais das respostas dos profissionais que estão na linha de frente do fazer pedagógico. Estatisticamente, os indicadores de criatividade desta escola indicam sua preocupação com a inclusão dos sujeitos. O olhar complexo, transdisciplinar e ecoformador presente nesta instituição, desde a proposta pedagógica até as práticas educativas, contribuiu sobremaneira para a manifestação desses resultados. No entanto, como se pode perceber, é imprescindível que as instituições que buscam pela via da criatividade a constituição de espaços inclusivos, jamais percam de vista a necessidade de valorizar individualmente as dimensões humanas do humano. 
Constatamos, ainda, que esse estudo colabora para o fortalecimento da interlocução entre as instituições e o crescimento da Rede Internacional de Escolas Criativas (RIEC). Por fim, tendo em vista que o desconhecido é uma função do conhecido, é possível afirmar que os achados desse estudo demandam novas investigações, dentre as quais explorar e propor mudanças ao instrumento VADECRIE, ampliando seus conceitos qualitativos e redistribuindo sua escala.

Assim, constatamos que, para que se possa superar práticas pedagógicas calcadas numa lógica clássica, e abrirmos as gaiolas epistemológicas é fundamental que os professores/as possam elevar as consciências no sentido da produção de uma escola para o século XXI, cujas formas hiperespecializadas sejam rompidas, e formas criativas de educar possam nortear a intervenção pedagógica. A reforma de pensamento no campo da educação implica investimento nos professores, investimento financeiro, mas também afetivo, de fazê-los se apaixonarem cotidianamente pela educação, para restabelecer laços.

\section{REFERÊNCIAS}

ALVES, Maria Dolores Fortes. O ser e o fazer-se professor: ressignificando valores, tecendo a teia da vida. Revista Internacional de Educación y Aprendizaje, v. 1, 2013.

ALVES, Maria Dolores Fortes. Práticas de aprendiragem integradoras e inclusivas: autoconhecimento e motivação. Rio de Janeiro: Wak, 2016.

ALVES, Maria Dolores Fortes; VIDINHA, Marly Socorro. Caminhos metodológicos da teia da diversidade: a pesquisa-ação pelo olhar do pensar complexo e transdisciplinar. In: Congresso Internacional Marista de Educação, 5., 2016, Olinda. Anais eletrônicos... Olinda: UFPE Pernambuco, 2016.

ALVES, Maria Dolores Fortes; PEREIRA FILHO, Adalberto Duarte. Inclusão: um direito à cidadania. Revista Filosofia Capital, Brasília. Edição Especial: Heranças e elementos educacionais, v. 12, p. 61-67, 2017.

BEHRENS, Maria Aparecida; OLIARI, Anadir Luisa Thomé. A evolução dos paradigmas na educação: do pensamento científico tradicional à complexidade. Diálogos Educacionais, Curitiba, v. 7, n. 22, p. 53-66, 2007.

BOAVENTURA, Edivaldo. Educação planetária em face da globalização. Revista da FAEEBA Educação e Contemporaneidade, Salvador, n. 16, p. 27-35, 2001.

CANGUILHEM, George. O normal e o patológico. 6. ed. Rio de Janeiro: Forense Universitária, 2009. FREIRE, Paulo. Pedagogia da autonomia. São Paulo: Cortez, 2018.

FREUD, Sigmund. The relation of the poet to daydreaming. In: Creativity and the unconcious. New York: Harper \& How, 1958.

MORAES, Maria Cândida. Pensamento eco-sistêmico: educação, aprendizagem e cidadania no século XXI. São Paulo: Vozes, 2004.

MILIAN, Queila Guise; WECHSLER, Solange Muglia. Avaliação integrada da inteligência e criatividade. Revista de Psicologia, v. 36, p. 525-548, 2018.

MORÁN, José. Mudando a educaşão com metodologias ativas. Paraná: UEPG, 2014.

MORIN, Edgar. O método 1: a natureza da natureza. Porto Alegre: Sulina, 2005.

MORIN, Edgar. Introdução ao pensamento complexo. Trad. Eliane Lisboa. 3. ed. Porto Alegre: Sulinas, 2007. 
MORIN, Edgar. Em busca dos fundamentos perdidos. Porto Alegre: Sulina, 2003.

MORIN, Edgar. A cabeça bem-feita: repensar a reforma, reformar o pensamento. 21. ed. Rio de Janeiro: Bertrand, 2015.

ONG. Relatório de atividades desenvolvidas em 2016: unidade Maceió. São Paulo: SOSKINDERDORFF International, 2017.

TORRE, Saturnino de La; PUJOL, Maria Antonia. Transdisciplinaridad y ecoformación. Madrid: Universitas, 2007.

TORRE, Saturnino de La. Instituciones Educativas Creativas. Instrumento para valorar el desarrollo creativo de las instituciones educativas (Vadecrie). Sitges: Editorial Círculo Rojo - Investigación, 2012.

SUANNO, Marilza Vanessa Rosa. Docência universitária e práticas pedagógicas inovadoras. In: CONPEEX - Congresso de Pesquisa, Ensino e Extensão, 6., 2009, Goiânia. Anais eletrônicos... Goiânia: PUC-Goiás, 2009. p. 8249-8253.

SUANNO, João Henrique. Escola Criativa e práticas pedagógicas transdisciplinares e ecoformadoras. 2013. 230f. Tese (Doutorado em Educação) - Universidade Católica de Brasília, Brasília, 2013.

SAMPIERI, Roberto Hernández; COLLADO, Carlos Fernández. Metodología de la investigación. México: McGraw-Hill, 2013.

YIN, Robert K. Estudo de caso: planejamento e métodos. 3. ed. Porto Alegre: Bookman, 2005.

Submetido em fevereiro de 2021 Aprovado em maio de 2021

\section{Informações do(a)(s) autor(a)(es)}

Adalberto Duarte Pereira Filho

Bolsista da Fundação de Amparo à Pesquisa de Alagoas pelo Programa de Pós-graduação em Educação da Universidade Federal de Alagoas

E-mail: adalberto-duarte@hotmail.com

ORCID: http://orcid.org/0000-0001-5583-6305

Link Lattes: http://lattes.cnpq.br/163384104687598

Maria Dolores Fortes Alves

Programa de Pós-graduação em Educação da Universidade Federal de Alagoas

E-mail: mdfortes@gmail.com

ORCID: https://orcid.org/0000-0002-2292-8518

Link Lattes: http://lattes.cnpq.br/4130544132802418 